\title{
LA REFORMA LABORAL, LA PRECARIZACIÓN DEL TRABAJO Y EL PRINCIPIO DE ESTABILIDAD EN EL EMPLEO*
}

\author{
LABOR ACT REFORM, LABOR PRECARIOUSNESS \\ AND THE PRINCIPLE OF EMPLOYMENT STABILITY \\ RÉFORME DU TRAVAIL, LA PRECARISATION DU TRAVAIL \\ ET LE PRINCIPE DE STABILITE DE L'EMPLOI
}

\section{Carlos Sergio QuiÑOnES TINOCO*** Salvador RODRÍGUEZ LUGO***}

\begin{abstract}
RESUMEN: Las variaciones en el derecho constituyen adaptaciones a la realidad social; se dan como consecuencia de los cambios en los modelos sociales, culturales, económicos y del desarrollo tecnológico, que generan nuevas técnicas de producción. El problema que deriva de estas adaptaciones o cambios en la legislación laboral es de fondo, y tiene que ver con el giro o sentido que tomen. Son causa de preocupación las tendencias economicistas que orientaron la reforma de la Ley Federal del Trabajo de 2012, que tienen como principales referentes a la productividad y a la competitividad. Las nuevas disposiciones relativas a las formas atípicas de contratación para el trabajo constituyen una antinomia en relación con el artículo 2o. de la LFT, pues no existe congruencia entre el propósito de propiciar un trabajo digno o decente y la flexibilización de los derechos laborales, generando como consecuencia una incertidumbre y una precarización del trabajo, así como una inestabilidad en el empleo.
\end{abstract}

Palabras clave: Reforma laboral, precarización, inestabilidad en el empleo.

\footnotetext{
* Recibido el 14 de marzo de 2014 y aceptado para su publicación el 23 de marzo de 2015.

** Investigador en el Instituto de Investigaciones Jurídicas de la Universidad Juárez del Estado de Durango, México (carlosergioq@yahoo.com.mx).

*** Investigador en el Instituto de Investigaciones Jurídicas de la Universidad Juárez del Estado de Durango, México(rols482000@yahoo.com.mx).
} 
ABSTRACT: Variations in law are constituted by adaptations to social reality, they happen as a consequence of changes in social, cultural, economic and technological development models, which generates new production techniques. These adaptations and changes in labor legislation create a problem in its substance, which is related to the sense they take. The economic tendencies which have productivity and competitiveness as principal references that oriented the reform to Federal Labor Act of 2012 are a cause of concern. The new dispositions relative to atypical forms of hiring constitute an antinomy with the 2 nd article of the Federal Labor Act because there is no congruence between the purpose of promoting decent or dignified labor and labor rights' flexibility, generating a consequence of uncertainty, labor precariousness and employment instability.

Key Words: Labor reform, labor precariousness, employment instability.

RÉSUMÉ: Les variations de la loi constituent des adaptations à la réalité sociale; elles sont les conséquences de changements des modèles sociaux, culturels, et économiques et du développement technologique, qui génère de nouvelles techniques de production. Le problème qui découle de ces adaptations ou changements dans la législation du travail est de fond et il le tournant ou la direction qu'ils prennent. Ils sont un sujet de préoccupation des tendances économiques qui orientent la réforme de la loi fédérale du travail en 2012, qui ont comme référence principale la productivité et la compétitivité. Les nouvelles dispositions relatives aux formes atypiques de recrutement pour le travail constituent une antinomie quand on pense à l'article 2o. de la Loi Fédérale du Travail, car il n'y a aucune congruence entre le but de proposer un travail décent et la flexibilisation des droits du travailleur, générant incertitude, précarisation et instabilité dans l'emploi.

Mots-clés: La réforme du travail, précarisation du travail, instabilité de l'emploi.

SUMARIO: I. Nociones preliminares. II. En nuestro pais: nuevos paradigmas, frente a la tradición y los ensayos en las diferentes ramas del derecho. III. La propuesta de Habermas y su implementación. Algunas de las normas de ejecución y desarrollo. IV. Principios del derecho del trabajo. V. Las transformaciones del derecho del trabajo. VI. Pérdida de los derechos laborales. VII. Precarización del trabajo y debilitamiento del principio de estabilidad en el empleo. VIII. Conclusiones. IX. Bibliografía. 


\section{NOCIONES PRELIMINARES}

S

i consideramos al trabajo, en una posición conservadora y tradicional, como toda actividad humana, intelectual o material, independientemente del grado de preparación técnica requerido por cada profesión u oficio, pudiera parecer que nuestra visión no coincide con los tiempos que vivimos, en los que permea un interés económico, en el cual lo importante es la producción.

Aceptando la finalidad del mismo (del trabajo), en una postura tradicionalista-idealista, conformamos una estructura epistemológica en torno a un idealismo, promoviendo una tulela normativa que desembocaría en el reconocimiento de los derechos sociales, los cuales a su vez recibirían el resguardo del derecho del trabajo. Para su comprensión, a éste lo definimos, siguiendo a Mario de la Cueva, como "el conjunto de normas que el pueblo y el poder legislativo ha otorgado a los trabajadores garantizadas en la Constitución y en la Ley del trabajo"; ${ }^{1}$ en la misma obra del autor referido se contiene que el derecho del trabajo, si bien es un derecho inconcluso, es un derecho imperativo e incuestionablemente protector de la clase trabajadora.

Sin embargo, en una postura sociológico-jurídica crítica se aprecia una posición diferente, ubicando al derecho del trabajo como "una categoría histórica que surge y se desarrolla en el modo de producción capitalista”. Guamán Hernández y Illueca Ballester, ${ }^{2}$ refiriéndose al tema, establecen lo siguiente:

Desde este punto de vista, sus orígenes son eminentemente funcionales al sistema económico vigente en un sentido muy concreto: pretende regular las condiciones de explotación de los trabajadores y garantizar la reproducción y el mantenimiento de las relaciones capitalistas de producción. No obstante, siendo este su origen primigenio, debe reconocerse que el Derecho del Trabajo es también el resultado de una transacción histórica, una especie de armisticio entre el capital y trabajo conseguido en buena medida a través de las luchas de la clase obrera.

1 Cueva, Mario de la, El nuevo derecho mexicano del trabajo, 9a. ed., México, Porrúa, 1984, t. I, p. 96.

2 Guamán Hernández, Adoración e Illueca Ballester, Héctor, El huracán neoliberal. Una reforma laboral contra el trabajo, Madrid, Sequitur, 2012, p. 13. 
Esta época, caracterizada por una postura posmodernista, ha torcido un proceso evolutivo natural, encumbrando un nuevo paradigma en la cosmovisión del mundo jurídico, en el cual ahora impera el factor económico, girando, en consecuencia, el interés creativo y organizador en torno a provechos monetarios.

Para comprender el Estado de derecho bajo la aparición de paradigmas, es conveniente considerar la postura sostenida por Kahn: "Tenemos que recordar que Estado de derecho no es ni una cuestión de verdad revelada ni de orden natural. Es una forma de organizar una sociedad bajo un conjunto de creencias que son constitutivas de la identidad de una comunidad y sus miembros individuales". 3

El universo jurídico no está exento de ese influjo; de esa manera, la evolución del derecho transita en torno a los paradigmas predominantes.

Habermas, al referirse a la evolución del derecho y de los paradigmas, sostiene que las formas jurídicas no tienen un carácter perpetuo, sino que han sufrido transformaciones y generado su desarrollo por los cambios que han tenido las sociedades, particularmente en el mundo occidental, a partir del advenimiento de la modernidad.

Este filósofo no evade considerar que los diferentes modelos de sociedad han influido en los sistemas jurídicos, determinando su desarrollo y también sus limitaciones.

En otros campos, diferentes al derecho, se integra una enorme lista de nuevos paradigmas que reflejan cambios, en busca de una mejoría para el género humano.

La búsqueda de cambio para mejorar, que se da con frecuencia, en ocasiones se ve obstaculizada, produciéndose estancamientos y retrocesos que desvirtúan el paradigma.

\section{EN NUESTRO PAÍS: NUEVOS PARADIGMAS, FRENTE A LA TRADICIÓN Y LOS ENSAYOS EN LAS DIFERENTES RAMAS DEL DERECHO}

Pensar que en el derecho se propusieran nuevos paradigmas, pudiera considerarse como poco probable, tomando en cuenta que uno de los objetivos

3 Kahn, W. Paul, El análisis cultural del derecho. Una reconstrucción de los estudios jurídicos, Barcelona, Gedisa, 2001, p. 15. 
de ese instrumento de convivencia social (recordemos que el derecho es un vocablo polisémico) consiste en proporcionar seguridad jurídica, y dentro de los argumentos que se formulan para su justificación, el principal argumento es la permanencia y la vigencia de su cuerpo normativo; sin embargo, con una visión social dinámica, y aceptando que el derecho forma parte de un universo donde el cambio se produce permanentemente, su transformación se produce como una consecuencia natural de la inmanente evolución del ser social. Habermas propone un nuevo paradigma vinculado a la metodología de los procesos para resolver asuntos contemplados en su fase de conocimiento jurídico.

\section{LA PROPUESTA DE HABERMAS Y SU IMPLEMENTACIÓN. AlguNAS DE LAS NORMAS DE EJECUCIÓN Y DESARROLLO}

Quizá por un prurito de autonomía, cuando se estudian los cambios del derecho en relación con la transformación social, se afirma que no surge de los juristas la explicación científica de esos cambios, lo cual pareciera que el derecho es una cuestión autónoma de la sociedad; sin embargo, los procesos de cambio social necesariamente inciden en la actualización del derecho, y es a los juristas a quienes les compete su explicación.

Hablar de paradigmas es referirnos a un modelo que recurre a la epistemología, generando teorías, modelos, elementos y hasta acciones de ejecución.

Es conveniente considerar que al citar a los paradigmas en materia del derecho no nos concretamos al dictado de resoluciones o a la creación de normas jurídicas en una labor del legislador. Por ello, es necesario aclarar que la referencia a un paradigma jurídico abarca a toda una concepción de la cultura jurídica, lo que nos obliga a una permanente atención de los cambios sociales, que repercuten en cambios de la estructura legal y en la misma cultura del derecho.

Habermas ${ }^{4}$ identifica dos paradigmas en la evolución histórica del derecho. El primero de ellos ubica el todo jurídíco dentro de un Estado burgués, identificando su origen en una sociedad que centraba sus intereses en la economía y en la concepción de un derecho individualista, además de contar con un uni-

4 Dodds Berger, Daniel Alejandro, "Paradigmas del derecho, reflexión y derechos sociales”, Derecho y Humanidades, Santiago, núm. 18, 2011, pp. 99-111, www.derechoyhumanidades.uchile. cl/index.php/ $\mathrm{RDH} /$ article. 
verso normativo en el que persistía un orden estructurado y predecible, y con un postulado basado en la seguridad jurídica de un Estado-gobierno, donde primaba un universo de normas generales y desarollándose en un plano de libertades codificadas.

El segundo, debido a un proceso de reflexión, no exento de convulsiones sociales, surge como un nuevo paradigma: el del derecho del Estado social, apareciendo en la búsqueda de equilibrio en las relaciones sociales y proyectando una cobertura proteccionista a favor de grupos sociales, como la familia, los obreros, los campesinos, y bajando, consecuentemente, del pedestal en el que se sostenía al individuo por parte del Estado burgués.

Sin embargo, surgieron nuevas interrogantes, que no pueden ser resueltas en un modelo social, y que fueron dejadas de lado por el modelo individualista, con lo que apareció una nueva propuesta de paradigma, a la que se denomina como "procedimental", que fue visualizada como una respuesta a la tensión que se genera entre lo colectivo y lo individual, entre sistema y mundo de la vida.

En este paradigma se busca una postura menos ingenua, persiguiendo superar la simplicidad del derecho liberal y el paternalismo del Estado social en las soluciones que propone, resultando sugerencias de arreglos conducidos legalmente a través de reglas, que perfeccionadas surgen, según Habermas, del siguiente razonamiento.

La evolución del derecho y de los paradigmas, tratándose de las formas jurídicas, no tienen un carácter perpetuo, sino que han sufrido transformaciones y desarrollo por los cambios que han tenido las sociedades.

Este filósofo no evade considerar que los diferentes modelos de sociedad han influido en los sistemas jurídicos, determinando su desarrollo y sus limitaciones.

Según la visión de Habermas, se interrumpió el proceso progresivo natural para, en un proceso regresivo, reencumbrarse un individualismo a ultranza.

En la euforia de la consolidación del derecho del trabajo, en su concepción tradicionalista se enumeraron una serie de principios reguladores de su existencia, llegándose a sostener que éstos "constituyen el fondo filosófico, ético y jurídico de nuestra disciplina". ${ }^{5}$ De esa manera, se destacaron como fundamentales los siguientes principios:

\footnotetext{
5 Cueva, Mario de la, op. cit., p. 107.
} 
- El trabajo es un derecho y un deber social.

- Libertad y derecho de trabajo.

- Igualdad y derecho de trabajo.

- Respeto a la dignidad humana.

- Condiciones decorosas para el trabajador.

- Principio de responsabilidad en una concepción social.

Lastra Lastra, en un artículo publicado en el Boletín Mexicano de Derecho Comparado, cita los principios ordenadores de las relaciones de trabajo, anteponiendo como premisas lo siguiente:

La llamada socialización del derecho como una tendencia universal no constituye una fórmula vacía, sino que es un fenómeno histórico, producido por las condiciones y exigencias de la vida social y económica de nuestro tiempo. La expresión Derecho Social ha sido censurada por quienes utilizan la pureza conceptual, porque en un sentido amplio, todo el derecho es social. Sin embargo, con esta locución se ha querido significar una nueva dimensión jurídica, más humana, más justa, que penetra profundamente en la entraña misma de la naturaleza del hombre.

En los dominios de lo jurídico, la socialización se traduce en una reglamentación imperativa de las relaciones humanas que deja a la autonomía individual sumamente restringida.

En el artículo 123 de la Constitución Política de los Estados Unidos Mexicanos se contienen los principios de libertad, dignidad y salud; además, se contempla a los siguientes elementos:

- La imperatividad del derecho.

- El principio in dubio pro operario.

- Estabilidad y continuidad en el trabajo.

- Principio de igual salario para igual trabajo.

- Libertad sindical. ${ }^{6}$

Sin embargo, es evidente que la pretensión de estabilidad y continuidad en el trabajo se ha visto menoscabada en la reciente reforma laboral que ha

6 Lastra Lastra, José Manuel, "Principios ordenadores de las relaciones de trabajo", Boletín Mexicano de Derecho Comparado, México, núm. 100, enero-abril de 2001, wnw.biblio.juridicas.unam. $m x$, consultado el 10 de marzo de 2014. 
vivido México. Así, la finalidad que impulsó la defensa de este principio pareciera que no cuenta con argumentos validos en la contemporaneidad, bajo el pretexto de mantener inhiestos los principios del neoliberalismo y lograr un sitial de competencia productiva en el universo de la globalización.

Razonar que la estabilidad evita al trabajador el riesgo de quedar constantemente sin empleo, cambiar con frecuencia el régimen de vida y, a veces, el lugar de residencia, ${ }^{7}$ ya no es suficiente; la demostración objetiva de que la ineficiencia es consecuencia de una mala administración se oculta para imputar al trabajador el peso de la responsabilidad.

Sin estabilidad, los trabajadores vivirían con la inseguridad y la psicosis del presente y del mañana, tal como lo sostiene Lastra en la obra referida.

Pareciera que en esta época de la globalización económica, la precariedad en el trabajo fuera la solución, imponiendo en las relaciones laborales una flexibilidad contra toda lógica sociojurídica, y abatiendo el edificio filosófico del derecho, las garantías sociales y los derechos humanos de los trabajadores.

Mario de la Cueva sostenía que la estabilidad en el trabajo apareció en nuestro derecho como una de las manifestaciones más cristalinas de la justicia social, "...porque su finalidad inmediata es el vivir hoy y en el mañana inmediato”. Este autor define a la estabilidad en el trabajo de la siguiente manera:

La estabilidad en el trabajo es un principio que otorga carácter permanente a la relación de trabajo y hace depender su disolución únicamente de la voluntad del trabajador y sólo excepcionalmente de la del patrono, del incumplimiento grave de las obligaciones del trabajador y de circunstancias ajenas a la voluntad de los sujetos de la relación, que hagan imposible su

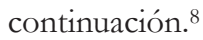

\section{PRINCIPIOS DEL DERECHO DEL TRABAJO}

El reconocimiento de derechos y garantías sociales en la Constitución mexicana de 1917 significó un proceso de apertura para la reivindicación de derechos que nacen junto con el comienzo de la relación de trabajo y son inseparables de ésta; son derechos sustentados en principios de justicia social

\footnotetext{
7 Idem.

8 Cueva, Mario de la, op. cit., p. 219.
} 
establecidos en el artículo 123 constitucional, que de acuerdo con Néstor de Buen Lozano establecen "el equilibrio en la relaciones entre trabajadores y patrones, la justicia social, el trabajo como derecho y deber social, la libertad, la igualdad, la dignidad y la salud de los trabajadores".

La concepción del trabajo como derecho y deber social, establecida en el artículo 123 de la Constitución, contiene alcances y limitaciones que se encuentran definidos en la propia Constitución en forma de directrices políticas, principios y normas. El sustento teórico acerca de los principios y directrices políticas que proporciona Donald Dworkin auxiliarán en su identificación. De acuerdo con este jusfilósofo, el concepto "directrices políticas" se refiere "al tipo de estándar que propone un objetivo que ha de ser alcanzado; generalmente, una mejora en algún rasgo económico, político o social de la comunidad"; 10 en tanto que el concepto "principio" se refiere a "un estándar que ha de ser observado... porque es una exigencia de la justicia, de la equidad o alguna otra dimensión de la moralidad". ${ }^{11}$ Por su parte, las normas son prescripciones que como mandatos de optimización establecen derechos y deberes, así como los procedimientos para efectivizar la realización de los primeros.

Según Mario de la Cueva — citado por Kurczyn—:

Los principios jurídicos, o caracteres, en derecho mexicano del trabajo, lo consideran un derecho unitario de clase, expansivo, inconcluso, imperativo, protector de la clase trabajadora. La doctrina mexicana distingue los caracteres de las finalidades: el derecho y el deber sociales, la libertad, la igualdad, la responsabilidad, la dignidad humana y la existencia decorosa.

En virtud de que la reforma laboral de 2012 sólo afectó a la Ley Federal del Trabajo, las garantías individuales y sociales relacionadas con el trabajo, que establecen los artículos 5o. y 123, respectivamente, siguen vigentes; sin embargo, existe una tendencia hacia la flexibilización en las relaciones de trabajo — materializada en el texto reformado de la Ley Federal del Trabajolo cual puede ser válido en "tanto no afecte los principios generales del derecho del trabajo".

\footnotetext{
9 Dworkin, Ronald, Los derechos en serio, trad. de Marta Guastavino, Barcelona, Ariel, 2002.

10 Ibidem, p. 72.

11 Idem.
} 
Si bien es cierto que no debe perderse de vista que la inserción de México en los mercados globales es necesaria y exige una adaptación y la implementación de nuevas formas de organización para el trabajo que permitan elevar la productividad y generar condiciones de competitividad en tales mercados, esto no debe ser óbice para conservar la vigencia de los principios generales del derecho del trabajo; ante los procesos de flexibilización, que se han traducido en efectos negativos para los trabajadores, consideramos que es necesario refrendar los principios jurídicos básicos del derecho del trabajo: “equilibrio y justicia social, el trabajo como derecho y deber sociales, libertad, dignidad, decoro, imperatividad e irrenunciabilidad", que garanticen un "mínimo fundamental" de protección a los trabajadores.

\section{LAS TRANSFORMACIONES DEL DERECHO DEL TRABAJO}

Con el surgimiento de los procesos de globalización, la mundialización del capital y el neoliberalismo económico — fenómenos a los que México no puede sustraerse - se da comienzo a la etapa de participación en la economía global, poniendo fin al modelo económico de desarrollo compartido.

En este contexto, el derecho mexicano del trabajo ha tenido que enfrentar los retos que le imponen los siguientes factores: a) las transformaciones en las técnicas de producción que obligan a nuevas formas de organización para el trabajo; b) la prevalencia de los asuntos e intereses económicos y políticos; c) la tendencia globalizadora de la economía, y d) el pensamiento económico neoliberal que ha impuesto nuevos modelos económicos.

a) De acuerdo con lo expuesto por Alain Touraine, las transformaciones en las técnicas de producción han obligado: 1) a un tránsito o transformación de la producción en cadena, en la que son utilizadas máquinas operadas por trabajadores especializados, y 2) a la producción automatizada con la utilización de la informática, que elimina o reduce al mínimo las intervenciones manuales; este tránsito ha significado "una tercera revolución industrial" en la era científica, que con la automatización y con los cambios en la organización de los mercados ha generado el uso de medios no tradicionales de empleo. ${ }^{12}$

12 Cit. por Kurczyn Villalobos, Patricia, Las nuevas relaciones de trabajo, México, Porrúa, 1999, pp. 140-143. 
b) La prevalencia de asuntos e intereses económicos y políticos. Éstos se han materializado en procesos de diálogo y de concertación entre empresas, trabajadores y el Estado, mediante "acuerdos marco", con los que se han creado mecanismos de concertación social y acuerdos de carácter básicamente políticos sin una clara fundamentación legal para la atención de temas de interés nacional, que en ocasiones se han encaminado más a la resolución de problemas de orden político y económico, como la disminución de la inflación y el saneamiento de las finanzas públicas, aun cuando en dichos acuerdos se incluyan temas como los relativos a los salarios y sus aumentos, la productividad, la capacitación y los compromisos para mejorar las relaciones de trabajo; ${ }^{13}$ esto ha desembocado finalmente en la reforma a la Ley Federal del Trabajo promulgada en noviembre de 2012.

c) La tendencia globalizadora de la economía. La integración mundial de la economía ha traspasado los regionalismos y los nacionalismos, creando una totalidad compleja, que ha afectado las formas de relación social, a consecuencia de las nuevas formas de organización para el trabajo, la integración regional de las economías, en la cual participan varios países para lograr acuerdos o tratados de libre comercio, en los que

independientemente de los efectos que en materia económica puedan tener dichos instrumentos internacionales, es la manera como los temas sobre el trabajo se han venido abordando en tales acuerdos... bajo la denominación de la "cláusula social", el tema de los derechos de los trabajadores empieza a formar parte de las agendas de las negociaciones internacionales. ${ }^{14}$

Uno de los efectos de esta integración y de la inclusión del tema del trabajo en las agendas de las negociaciones internacionales ha sido la exigencia de desregulación de las condiciones rígidas y la introducción de la flexibilidad en las relaciones y condiciones de trabajo.

d) El pensamiento neoliberal que ha impuesto nuevo modelos económicos. La globalización es el resultado de una nueva interpretación del liberalismo, que se ha traducido en un sistema que ha impuesto sus propios paradigmas

13 Reynoso Castillo, Carlos, Derecho del trabajo, panorama y tendencias, México, UAM-Miguel Ángel Porrúa, 2006, pp. 148-151.

14 Ibidem, pp. 150 y 151. 
con un sentido utilitario muy cercano a un nuevo conservadurismo, que ha dado por resultado nuevas y mayores desigualdades económicas y sociales. ${ }^{15}$

Kurczyn Villalobos advierte que en la actualidad los desafíos laborales tienen tres enfoques: el económico, el jurídico y el humanista.

El enfoque económico obliga a analizar los datos de cambio de estructura laboral activa y de actitud de los trabajadores, atribuibles al cambio técnico; si la realidad muestra un descenso en los puestos de trabajo en las formas tradicionales, los adelantos técnicos requerirán nuevas actividades y otras formas de organización del empleo; en este caso, los problemas en el mercado de trabajo responden a factores inherentes a las políticas económicas. ${ }^{16}$

El enfoque jurídico tiene que ver con la aplicabilidad de las normas del derecho del trabajo "sin contrariar el espíritu general y universal que anima las relaciones estándares o clásicas"; ${ }^{17}$ el reto más actual es el de delimitar el dualismo y definir la ambivalencia del derecho del trabajo, un dualismo que se refiere a los modos de protección del trabajador: desde una primera óptica, lo económico debe condicionar lo social; es decir, "la protección está estrechamente relacionada con las condiciones económicas y particularmente con la situación de la empresa". ${ }^{18}$ Desde otro punto de vista, "esa protección constituye un factor determinante del progreso económico; por lo tanto, el derecho del trabajo puede anticiparse a la situación económica, e incluso la competitividad y productividad de las empresas pueden aumentar por el desarrollo de la protección social de los trabajadores". ${ }^{19}$ La aplicación de las normas laborales y la defensa de las garantías sociales sin frenar el progreso requieren de la determinación de los intereses de los trabajadores, los cuales se centran fundamentalmente en el rendimiento de los salarios, que deben ser suficientes para la vida activa y para el retiro del trabajador, y que constituyen la base "para vivir la existencia en los planos humanos de justicia y dignidad". ${ }^{20}$ Sin embargo, en la actualidad ha triunfado el primer enfoque; es decir, lo económico condiciona lo social, de tal suerte que prevalece el criterio

15 Rodríguez Lugo, Salvador y Quiñones Tinoco, Carlos Sergio, La relación laboral y el proceso de globalización, Durango, Universidad Juárez del Estado de Durango, 2010, pp. 72 y 73.

16 Kurczyn Villalobos, Patricia, op. cit., pp. 145 y 146.

17 Ibidem, p. 146.

18 Ibidem, p. 147.

19 Idem.

20 Idem. 
economicista que atiende primero a las condiciones de la empresa para poder determinar y reconocer derechos a los trabajadores; tal es el criterio que ha imperado en la reforma laboral de 2012.

El enfoque humanista implica "los retos para desafiar los valores, intereses de relevancia en el plano psicológico, sociológico y filosófico”; 21 en este plano se definen los factores que permiten el desarrollo personal y humano del trabajador; sin embargo, en la sustentación de la reforma laboral este enfoque se ha dejado de lado, tal y como lo demuestra el texto reformado del artículo 20. de la Ley Federal del Trabajo, que señala que "las normas de trabajo tienden a conseguir el equilibrio entre los factores de la producción...”, abandonando el enfoque humanista, al dejar de referirse a relaciones entre trabajadores y patrones; es decir, entre personas, por lo que la convocatoria que hace esta norma a conseguir, igualmente, la justicia social entre los factores de la producción, queda vacía de contenido, en virtud de que "justicia social” significa no sólo el mejoramiento de las condiciones económicas de los trabajadores, sino que también alcancen su dignidad como personas humanas. ${ }^{22} \mathrm{El}$ término "factores de la producción" es un concepto económico, que no identifica personas, sino tan sólo, en forma genérica, los elementos que intervienen en un proceso productivo; por tanto, la justicia social sólo es aplicable a personas.

Somos testigos de que en el mundo del trabajo se han venido configurando nuevas formas de explotación y dominación, que se concretizan en las diversas modalidades en que se presta el trabajo personal por cuenta ajena — tales como el trabajo por turnos, la prolongación no querida de la jornada de trabajo, los cambios de horario según las necesidades de la empresa, el trabajo en fines de semana-, a las que se agregan las nuevas tendencias, referentes a la subcontratación u outsourcing y de la contratación colectiva, y el reformismo de las leyes y reglamentos del trabajo.

El artículo 123 de la Constitución Política de los Estados Unidos Mexicanos establece que "toda persona tiene derecho al trabajo digno y socialmente útil".

Al amparo de este principio, la Ley Federal del Trabajo prescribía en su artículo 3o. lo siguiente: "El trabajo es un derecho y un deber sociales. No

21 Idem.

22 Trueba Urbina, Alberto y Trueba Barrera, Jorge, Ley Federal del Trabajo. Comentarios, prontuario, jurisprudencia y bibliografía, 81a. ed., México, Porrúa, 2000, p. 22. 
es artículo de comercio, exige respeto para las libertades y dignidad de quien lo presta y debe efectuarse en condiciones que aseguren la vida, la salud y un nivel económico decoroso para el trabajador y su familia”.

Pero con la reforma de 2012 a la Ley se suprimió la regla general, que exigía respeto para las libertades y la dignidad de quien lo presta, y que significaba una exigencia de justicia y de equidad.

El trabajo, según lo señala Kurczyn, "como satisfactor de las necesidades vitales del hombre, es un derecho natural; por lo tanto, deben crearse los instrumentos para hacerlo posible", tarea esta última que corresponde al Estado para garantizar la posibilidad de trabajar. El trabajo, como deber social, tiene como base fundamental el sentido de solidaridad, pues se produce para generar los satisfactores de las necesidades del grupo; sin embargo, enfrenta el propósito de los empresarios-empleadores de elevar los niveles de productividad y de ganancia, pero con menos responsabilidades, lo que se opone al sentido de solidaridad social. ${ }^{23}$

Kurczyn advierte que "las técnicas de organización y administración empresarial y de productividad en lo particular se amplían y se perfeccionan constantemente, ritmo no siempre igual en las políticas gubernamentales de empleo", ${ }^{24}$ y continúa señalando que se aplican las modificaciones con la participación privada, pero no se contemplan las modalidades de cambio en las contrataciones laborales y en los modos de trabajar. ${ }^{25}$

En nuestro país, las transformaciones del derecho del trabajo, ya reales, antes de la reforma de 2012 y que se implementaron con la práctica extralegal, derivan de factores económicos y políticos, tanto nacionales como internacionales. En la solución a los problemas laborales; por ejemplo, los altos índices de desempleo, el bajo poder adquisitivo del dinero, se ha pretendido como solución la ampliación del mercado, aceptando las fórmulas económicas propuestas por los organismos internacionales de crédito, que ahora han sido reflejadas en la multicitada reforma a la Ley Federal del Trabajo.

En las transformaciones del derecho del trabajo han jugado un papel preponderante los pactos y alianzas entre los factores de la producción, representados por los sindicatos de trabajadores y las organizaciones patronales,

\footnotetext{
23 Kurczyn Villalobos, Patricia, op. cit., p. 149.

24 Idem.

25 Idem.
} 
convocados por el gobierno, con el propósito de establecer mecanismos económicos para el desarrollo. Con ellos asistimos, desde las dos últimas décadas del siglo XX, a un cambio de rumbo de la economía mexicana, con el fin de insertarse en la economía global; así, en el periodo referido se puso en marcha una política antiinflacionaria, que tuvo como base el control de la inflación por encima de los aumentos salariales, los que se calculan a partir de los índices inflacionarios registrados en el año y no sobre los índices proyectados, lo que es contrario a las disposiciones constitucionales y legales que previenen que los salarios mínimos generales deben ser suficientes para satisfacer las necesidades normales de un jefe de familia en el orden material, social y cultural, y para proveer a la educación obligatoria de sus hijos.

El modelo neoliberal de la economía implementado en México y la inserción en la globalización económica habían generado nuevas pautas de regulación de las relaciones de trabajo, las cuales se plantearon fundamentalmente en dos instrumentos: el Acuerdo de Cooperación Laboral de América del Norte entre los gobiernos de los Estados Unidos Mexicanos, de Canadá y de los Estados Unidos, publicado el 21 de diciembre de 1993 en el Diario Oficial de la Federación, y los Principios de la Nueva Cultura Laboral, convenido el 13 de agosto de 1996 por el Ejecutivo federal y las principales organizaciones obreras y patronales.

Estas acciones tuvieron una tendencia a modificar o a dejar de lado los presupuestos establecidos en la Constitución y en la ley, considerados como mínimos necesarios para garantizar el alcance de un nivel económico y un nivel de bienestar decorosos. Además, el modelo neoliberal ha impuesto fórmulas económicas a los países emergentes, que han tenido en ellos efectos devastadores, empobreciendo cada vez más a los más necesitados y marginados, ante la falta de políticas que orienten el crecimiento de modo equitativo y que materialicen un programa para acabar con las desigualdades sociales y económicas y para hacer efectiva la aplicación de la justicia social, según testimonia Joseph Stiglitz —Premio Nobel de Economía 2001 y quien se desempeñara como vicepresidente del Banco Mundial- en su libro El malestar en la globalización. ${ }^{26}$

26 Stiglitz, Joseph, El malestar en la globalización, trad. de Carlos Rodríguez Brown, México, Santillana Ediciones Generales, 2010. 


\section{PÉRDIDA DE LOS DERECHOS LABORALES}

Las nuevas técnicas de producción que obligan a nuevas formas de organización para la producción, las tendencias globalizadoras de la economía y el comercio y el impulso de la ideología neoliberal, han propiciado la tendencia hacia la flexibilización laboral, que pretende modificar las condiciones en las relaciones de trabajo como una solución a la oposición de intereses entre el trabajo y el capital.

La relación de trabajo y el contrato de trabajo, de acuerdo con sus definiciones legales establecidas en la Ley Federal del Trabajo, según los principios del artículo 123 constitucional, constituyen los instrumentos que generan una relación jurídica entre el empleador y el trabajador, y que crea derechos y obligaciones para ambas partes; son los dispositivos legales que permiten a los trabajadores, acceder a las prestaciones y al ejercicio de las acciones y derechos asociados con el empleo en la esfera del derecho del trabajo.

Pero ya hemos señalado que la economía mexicana, y consecuentemente la realidad laboral nacional, se encuentran inmersas en el contexto mundial de la globalización, por lo que no puede sustraerse de las nuevas tendencias globalizadoras. La flexibilidad laboral actualmente es una realidad que funciona aproximadamente desde la década de los años ochenta del siglo pasado, de múltiples maneras, a partir de la instrumentación de los "pactos económicos" celebrados a instancias del Ejecutivo, por éste y los representantes de las organizaciones obreras y patronales, y que ahora ha sido formalizada con la reforma mencionada, la cual introdujo nuevas formas de contratación para el trabajo, cuya principal característica es la de que rompen con el principio de la estabilidad en el trabajo.

La flexibilidad, nos enseña Kurczyn, puede tener tres intenciones básicas:

a) La proteccionista: la flexibilidad como el instrumento que permite mejorar o superar las condiciones económicas o sociales del trabajador.

b) La de adaptación: en este caso, la intención es la de ajustar las condiciones conforme a las fluctuaciones del mercado, cuando resulta imposible la continuación de las relaciones entre trabajadores y empleadores debido a diversas causas, que deberán justificarse ante la junta de conciliación y arbitraje. 
c) La de desrregulación: ésta se materializa con reformas a la reglamentación aplicable a los trabajadores. ${ }^{27}$

Esta conjunción de intenciones de la flexibilidad en el trabajo, más que una protección a los trabajadores, como pudiera parecer, tiene el propósito de conseguir la abdicación de la intervención del Estado en la regulación de la economía, a fin de lograr, desde el punto de vista neoliberal, una economía libre de cualquier tipo de control y sólo regulada por las leyes de la oferta y la demanda, o que incluye, desde luego, la aplicación de estas leyes en el mercado de trabajo.

\section{PRECARIZACIÓN DEL TRABAJO Y DEBILITAMIENTO} DEL PRINCIPIO DE ESTABILIDAD EN EL EMPLEO

Con la reforma a la Ley Federal del Trabajo en 2012 se ha dado paso a un ideario fundamentalmente economicista, que vulnera los derechos sociales fundamentales; la lógica propia del derecho del trabajo es la de conseguir el equilibrio y la justicia social entre empleadores y trabajadores, y en consecuencia, frenar los posibles abusos de una situación de poder, que se traduce en posiciones de mando y obediencia. La flexibilización de los derechos laborales establecida por las reformas a la Ley Federal del Trabajo rompe con esta lógica, pues mientras que en el artículo 2o. de la Ley se establece que "las normas del trabajo tienden a conseguir el equilibrio entre los factores de la producción y la justicia social, así como propiciar el trabajo digno o decente en todas las relaciones laborales", las reformas y adiciones atienden a un pensamiento economicista, que busca desmantelar o flexibilizar un entramado de medidas de protección y respaldo al trabajador, y que le garantizaban estabilidad en el empleo, así como facilitar las supuestas inversiones, cuyo modelo de funcionamiento muchas veces es el de instalarse hasta en tanto convenga trasladarse a otro punto, por lo que requieren de un abaratamiento de la fuerza de trabajo, generando incertidumbre, trabajo precario e inestabilidad en el empleo, trasladando al trabajador los riesgos y responsabilidades.

27 Kurczyn Villalobos, Patricia, op. cit., pp. 123 y 124. 
Según Héctor Valle:

Porque la precariedad laboral no viene sólo con el hecho mismo del trabajo temporario, mal pagado y sin seguridad social sino que se inscribe en un modelo de inversión donde las fuerzas laborales son tomadas temporariamente, sin prácticamente contar con coberturas sociales suficientes, salvo unos pocos países en donde no sólo se mantienen legislaciones laborales que realmente atienden al trabajador sino que además se cumplen (Valle).

La conceptuación de trabajo digno establecida en el artículo 2o. reformado de la Ley Federal del Trabajo señala que es aquel trabajo en el que, entre otros elementos, se respeta plenamente la dignidad humana del trabajador; se tiene acceso a la seguridad social; se percibe un salario remunerador, y se recibe capacitación para el incremento de la productividad con beneficios compartidos.

Sin embargo, con la reforma laboral se han legalizado diversas formas de contratación, tales como contratos a prueba; los contratos de capacitación inicial; los contratos de temporada; los contratos a tiempo parcial; la subcontratación u outsourcing, que son formas de contratación que trasladan al trabajador los riesgos y provocan incertidumbre, toda vez que no garantizan seguridad en el empleo. Por otra parte, la reforma no contempla la regulación de las relaciones laborales derivadas de los contratos disfrazados de "contratos de prestación de servicios", en los que se dan las modalidades de contratación de trabajadores autónomos dependientes y los trabajadores falsos autónomos, lo que significa un fraude a la ley. Nos referimos al articulado que regula estos contratos, por encontrar en ellos las formas más evidentes de flexibilización de derechos laborales, de inestabilidad en el empleo y de precarización del trabajo.

Una característica de contrataciones a prueba y de capacitación inicial es que, según se desprende de los artículos 39 A y 39 B de la Ley, la determinación de si el trabajador acredita o no las capacidades o aptitudes necesarias para el desempeño del trabajo para el que fue contratado, se hace de manera discrecional por el patrón, quien aunque debe tomar en cuenta la opinión de la Comisión Mixta de Productividad, Capacitación y Adiestramiento, así como la naturaleza de la categoría o puesto, tiene la posibilidad de dar por terminada la relación de trabajo sin responsabilidad para él. Cabe precisar que 
no se encuentran definidas en la ley ni el papel que juega en estos procesos de prueba y de capacitación inicial la comisión referida ni los procedimientos de evaluación que en todo caso debería llevar a cabo para poder emitir una opinión objetiva al empleador.

Las relaciones de trabajo pactadas para labores discontinuas cuando los servicios requeridos sean para labores fijas y periódicas de carácter discontinuo, en casos de actividades de temporada o que no exijan la prestación de servicios toda la semana, el mes o el año, si bien pueden ser por tiempo indeterminado, tienen la característica de que son suspendidas a la conclusión de la temporada, con la consecuente suspensión de los derechos y obligaciones para ambas partes, sin responsabilidad para el trabajador y el patrón, según lo dispone el artículo 42, fracción VIII, de la Ley, que a la letra dice:

Artículo 42.- Son causa de suspensión temporal de las obligaciones de prestar el servicio y pagar el salario, sin responsabilidad para el trabajador y el patrón:

I. a VII...

VIII. La conclusión de la temporada en el caso de los trabajadores contratados bajo esta modalidad.

Esta suspensión surte efectos, según dispone el artículo 43, fracción V, "desde la fecha de conclusión de la temporada, hasta el inicio de la siguiente"; el peligro de inestabilidad en el empleo en este caso deriva de las disposiciones del artículo 45, que señala el momento en que el trabajador deberá regresar a su trabajo, refiriéndose a las hipótesis de suspensión de los efectos de las relaciones de trabajo contenidas en sus diversas fracciones, excepto la relativa a la suspensión por fin de la temporada, donde no se establece obligación alguna para el empleador de notificar al trabajador el momento en que inicie la temporada; esto, consideramos, implica el riesgo de que el trabajador sea despedido bajo el argumento de que no se presentó a trabajar en cierta fecha, que puede ser fijada discrecionalmente por el patrón.

Por lo que se refiere al régimen de subcontratación, caben las siguientes observaciones: del contenido de los artículos 15-A, 15-B, 15-C y 15-D se desprende que el régimen de subcontratación del trabajo lo convierte a éste en un artículo de comercio, contraviniendo el principio establecido en el artículo 3o. de la misma ley laboral, en virtud de que queda claro que la relación 
entre el contratante de los servicios o de la obra y el contratista que prestará los servicios o ejecutará la obra es una relación jurídica de carácter civil, pero debe advertirse que quien fija las tareas y supervisa el trabajo, el servicio o la ejecución que efectúa el contratista es el beneficiario, por lo que el trabajo que realizan los trabajadores se efectuará bajo la subordinación del contratante.

Una interpretación del artículo 15-A, en la parte relativa a las condiciones que deben satisfacerse para llevar a cabo la subcontratación, que se enuncian en los siguientes términos:

Artículo 15 A...

Este tipo de trabajo deberá cumplir con las siguientes condiciones:

a) No podrá abarcar la totalidad de las actividades, iguales o similares en su totalidad, que se desarrollen en el centro de trabajo.

b) Deberá justificarse por su carácter especializado;

c) No podrá comprender tareas iguales o similares a las que realizan el resto de los trabajadores al servicio del contratante...

Permite inferir los siguientes elementos:

1) Es posible la utilización de los trabajadores en actividades iguales o similares a las que se desarrollen en el centro de trabajo.

2) Los trabajos que realicen los trabajadores aportados por el contratista deben tener un carácter especializado, por lo que puede inferirse que podrán ser subcontratados también para efectuar tareas iguales o similares a las que se desarrollen en el centro de trabajo.

3) Parece incomprensible la contradicción entre los incisos "a" y "c".

4) El contratante de hecho y de derecho se convierte en patrón de los trabajadores bajo el régimen de subcontratación, pues el inciso "c" señala que "no podrá comprender tareas iguales o similares a las que realizan el resto de los trabajadores al servicio del contratante".

Estos resquicios, derivados de las condiciones establecidas para que pueda realizarse el trabajo bajo régimen de subcontratación, harán posible la elusión del cumplimiento de las obligaciones derivada de la relación laboral, en la que al trabajador no le quedará muy claro quién es su verdadero patrón, pues a diferencia de la intermediación, no existe una obligación solidaria entre el contratante y el contratista para garantizar el pago de las obligaciones, tanto 
las de carácter laboral como las de seguridad social, salvo en el caso de que no se satisfagan las condiciones señaladas, en cuyo caso el contratante se considerará patrón para todos los efectos de la ley.

Por otra parte, ha venido siendo una práctica la modalidad de los contratos de prestación de servicios, en los que la parte obligada a la prestación del servicio (autónomos dependientes y falsos autónomos) se ve obligada a llevarlo a cabo en las instalaciones del empleador, sujeto a un horario de trabajo, bajo sus órdenes y con los materiales y herramientas proporcionados por el mismo empleador, todo lo cual define una relación de trabajo subordinada a un patrón, pero que al tener su origen en un contrato de prestación de servicios, el empleador, amparado en dicho contrato, elude el pago de las prestaciones sociales.

Las anteriores formas de contratación constituyen un claro ejemplo de modalidades que generan incertidumbre, precarización del trabajo e inestabilidad en el empleo, pues el trabajador se encuentra sujeto a condiciones de trabajo desventajosas, ya que no se tiene ninguna certeza en cuanto a la duración del empleo; la relación de trabajo es encubierta o ambigua, y se está ante la imposibilidad de gozar de los beneficios y prestaciones que generalmente se asocian con el empleo, además de que enfrentan obstáculos para afiliarse a un sindicato.

\section{CONCLUSIONES}

Las variaciones en el derecho constituyen adaptaciones a la realidad de la vida, que se dan como consecuencia de los cambios en los modelos sociales, culturales, económicos y del desarrollo tecnológico, los cuales generan nuevas técnicas de producción. Estas variaciones se encuentran determinadas por el rumbo que toman dichos cambios, tales como nuevas formas de socialización, de relaciones culturales, innovaciones científicas y tecnológicas, y por otra parte, nuevas formas de organización para el trabajo y de desarrollo y de dependencias económicas entre las naciones, en las que las poderosas avasallan a las emergentes.

El problema que deriva de estas adaptaciones o cambios en la legislación laboral es de fondo, y tiene que ver con el giro o sentido que tomen. 
El derecho del trabajo se caracteriza como un derecho para desiguales, que se proyecta hacia el futuro como un derecho en expansión, esencialmente tutelar de los trabajadores, teniendo como fin y como principios básicos conseguir el equilibrio entre el trabajo y el capital, y obtener, asimismo, la justicia social en las relaciones entre trabajadores y patrones.

Son causa de preocupación las tendencias economicistas que orientaron la reforma de la Ley Federal del Trabajo de 2012, que tienen como principales referentes a la productividad y a la competitividad. Consideramos que si el hombre (el trabajador) deja de ser el principal referente para las transformaciones del derecho del trabajo, el trabajo pierde su sentido, pues dejará de ser socialmente útil para convertirse en el instrumento generador de riqueza sólo para unos cuantos.

Aunque en el artículo 2o. de la Ley Federal del Trabajo se establece que "las normas del trabajo tienden a conseguir el equilibrio entre los factores de la producción y la justicia social, así como propiciar el trabajo digno o decente en todas las relaciones laborales", las nuevas disposiciones relativas a las formas atípicas de contratación para el trabajo constituyen una antinomia en relación con el artículo señalado, ya que no existe congruencia entre el propósito de propiciar un trabajo digno o decente y la flexibilización de los derechos laborales que implican los artículos 15-A, 15-B, 15-C, 15-D, 38-A, 39-B, 42, fracción VIII, entre otros, y que han generado como consecuencia incertidumbre y precarización del trabajo, así como inestabilidad en el empleo. Así pues, se ha perdido de vista que el derecho a un trabajo digno o decente, como derecho fundamental, debe ser garantizado por el Estado, en los términos de los artículos 1o. y 123 constitucionales.

\section{BiBLIOGRAFÍA}

Cueva, Mario de la, El nuevo derecho mexicano del trabajo, México, Porrúa, 1984, t. I.

DodDs Berger, Daniel Alejandro, "Paradigmas del derecho, reflexión y derechos sociales", Derecho y Humanidades, Santiago, núm. 18, 2011, wmm. derechoyhumanidades.uchil.cl/index.php/ $\mathrm{RDH} /$ article.

DwOrkin, Ronald, Los derechos en serio, trad. de Marta Guastavino Barcelona, Ariel, 2002. 
Guamán Hernández, Adoración e Illueca Ballester, Héctor, El buracán neoliberal. Una reforma laboral contra el trabajo, Madrid, Sequitur, 2012.

KAHN, Paul W., El análisis cultural del derecho. Una reconstrucción de los estudios jurídicos, Barcelona, Gedisa, 2001.

Kurczyn Villalobos, Patricia, Las nuevas relaciones de trabajo, México, Porrúa, 1999.

LASTRA LASTRA, José Manuel, "Principios ordenadores de las relaciones de trabajo", Boletín Mexicano de Derecho Comparado, núm. 100, enero-abril de 2001, www.biblio.juridicas.unam.mx, consultado el 10 de marzo de 2014.

Reynoso Castillo, Carlos, Derecho del trabajo, panorama y tendencias, México, UAM-Miguel Ángel Porrúa, 2006.

Rodríguez LugO, Salvador y QuiÑONES TINOCO, Carlos Sergio, La relación laboral y el proceso de globalización, Durango, Universidad Juárez del Estado de Durango, 2010.

STIGLITZ, Joseph, El malestar en la globalización, trad. de Carlos Rodríguez Brown, México, Santillana Ediciones Generales, 2010.

Trueba UrbinA, Alberto y TruebA BArRerA, Jorge, Ley Federal del Trabajo. Comentarios, prontuario, jurisprudencia y bibliografía, 81a. ed., México, Porrúa, 2000. गु 